\title{
SCIENTIFIC REPORTS

\section{OPEN Characterizing pollution and source identification of heavy metals in soils using geochemical baseline and PMF approach}

\author{
Hui-Hao Jiang ${ }^{1,2}$, Li-Mei Cai ${ }^{1,2,3^{*}}$, Han-Hui Wen ${ }^{4} \&$ Jie Luo ${ }^{1,2}$
}

It is necessary to establish local geochemical baseline concentrations (GBCs) due to the lack or the inapplicability of regional background values in the study area. The establishment of GBCs of heavy metal (HM) in soil helps in making the accurate assessment of pollution, and then provides a basis for pollution control. Based on this, a case study was undertaken to study the GBCs of the Jiedong District, Guangdong Province, $\mathrm{China}$. In this research, cumulative frequency distribution curves were utilized to determine the local $\mathrm{GBCs}$ in the subsoils. The determined $\mathrm{GBCs}$ of $\mathrm{Cr}, \mathrm{Hg}, \mathrm{As}, \mathrm{Pb}, \mathrm{Ni}, \mathrm{Cd}, \mathrm{Cu}, \mathrm{Zn}, \mathrm{Co}$ and $V$ were $39.91,0.072,11.48,47.62,12.70,0.17,14.22,64.54,6.31$, and $68.14 \mathrm{mg} / \mathrm{kg}$, respectively. The average concentrations of $\mathrm{Hg}, \mathrm{As}, \mathrm{Pb}, \mathrm{Cd}, \mathrm{Cu}$ and $\mathrm{Zn}$ in the topsoils exceeded the corresponding baseline concentrations. In particular, the contents of $\mathrm{Cd}$ and $\mathrm{Hg}$ were 1.53 and 2.22 times higher than $\mathrm{GBCs}$. According to this baseline criterion, enrichment factor (EF), pollution load index (PLI) and ecological risk index (RI) were applied to assessing HM pollution. EF and PLI suggested that most areas were under moderate contamination, while $\mathrm{Hg}$ and $\mathrm{Cd}$ pollution was more serious. And the RI values presented that the potential ecological risks were low in most parts of the study area. The possible origins of HMs were identified by combining positive matrix factorization with EF and geostatistics. Comprehensive analysis indicated that $\mathrm{Hg}$ and $\mathrm{Cd}$ were related to industrial activities, such as textile and garment processing, plastic and rubber production and metal manufacturing. Arsenic and part of Cu mainly came from agricultural activities, namely the use of pesticides, fertilizers and livestock manures. Lead and Zn were mainly attributed to traffic emissions. Chromium, $\mathrm{Ni}, \mathrm{V}, \mathrm{Co}$, and part of $\mathrm{Cu}$ were originated from natural source controlled by parent materials. The corresponding contributions of these sources were $20.61 \%$, $24.20 \%, 19.22 \%$ and $35.97 \%$, respectively. This work provides information to prevent and control the soil HM pollution by proposing the efficient management of anthropogenic sources.

In recent years, soil pollution has become increasingly severe due to rapid industrialization and the increase of urban population ${ }^{1-3}$. Soil heavy metal (HM) pollution has received wide concern owing to the strong toxicity, bioavailability and persistence of $\mathrm{HMs}^{4}$. The high content of HMs in soil not only directly affects nutrients, structure and function of soil, reduces the biological activity of soil, but also adversely affects food quality and human health ${ }^{5,6}$. HMs in the soil pose a grave threat to human body through skin contact, inhalation and ingestion ${ }^{7}$. For example, cadmium can cause cardiovascular and cerebrovascular diseases and renal dysfunction ${ }^{8}$. Long-term exposure to lead-contaminated environments can result in serious damage to nerves, hematopoietic systems, and kidneys ${ }^{9}$. Therefore, HM pollution in soil is particularly concerned worldwide and urgently needs to be resolved.

Determining the pollution level and potential sources is the key to solving the problem of HM contamination in soil ${ }^{11,11}$. Geochemical baseline concentrations (GBCs) refer to the natural levels of HMs in the soil that do not include the effects of anthropogenic activities ${ }^{12,13}$. On the one hand, the background values (BVs) generally are reference values for a wide range of areas, which may not be applicable for specific small-scale study areas. On the

\footnotetext{
${ }^{1}$ Key Laboratory of Exploration Technologies for Oil and Gas Resources (Yangtze University), Ministry of Education, Wuhan, 430100, China. ${ }^{2}$ College of Resources and Environment, Yangtze University, Wuhan, 430100, China. ${ }^{3}$ Key Laboratory of Mineralogy and Metallogeny, Guangzhou Institute of Geochemistry, Chinese Academy of Sciences, Guangzhou, 510640, China. ${ }^{4}$ No.940 Branch of Geology Bureau for Nonferrous Metals of Guangdong Province, Qingyuan, 511500, China. *email: clmktz88@yangtzeu.edu.cn
} 


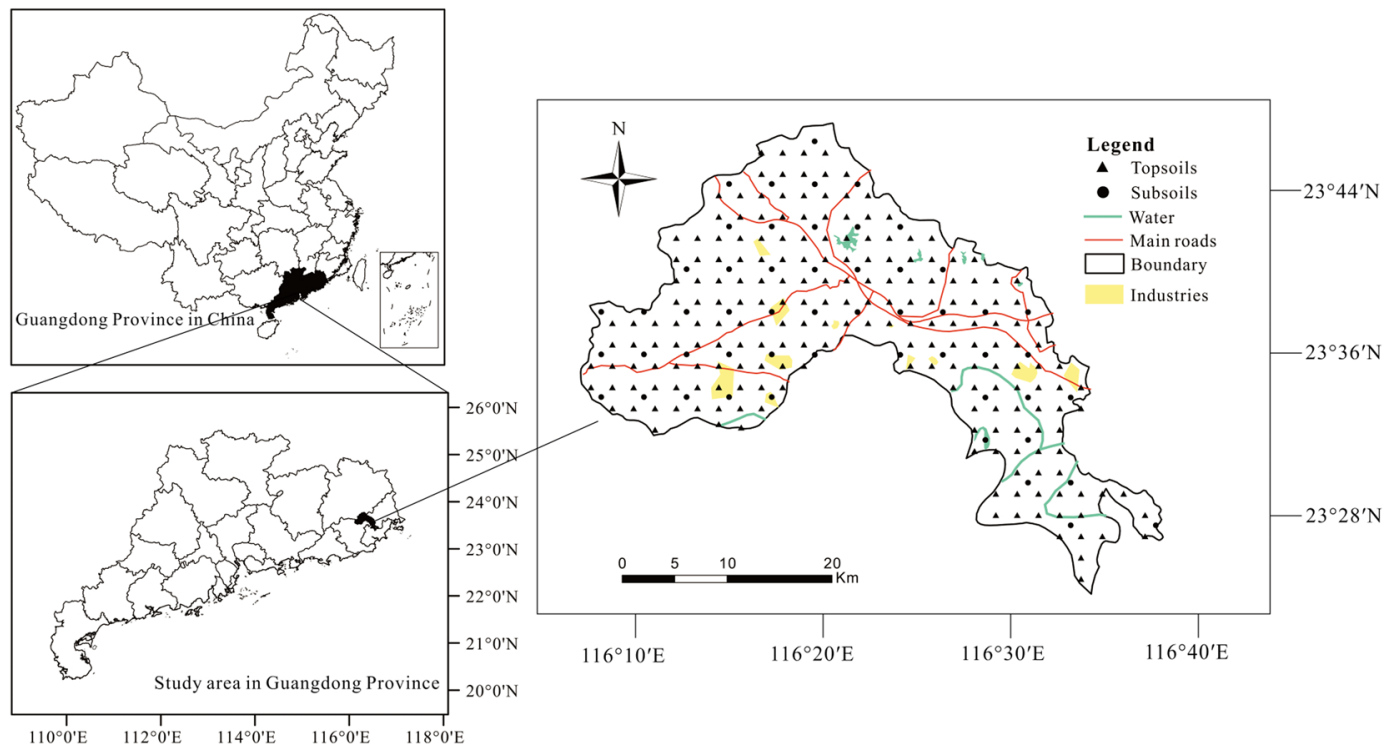

Figure 1. Location of the Jiedong District and distribution of sampling sites.

other hand, many areas lack BVs. Therefore, it is necessary to establish local GBCs $s^{14,15}$. The result of some widely used quantitative indicators in pollution assessment, such as ecological risk index (RI), pollution load index (PLI), contamination factor $(\mathrm{CF})$, and enrichment factor $(\mathrm{EF})$, will be more accurate when regional GBCs are used. As a result, establishing $\mathrm{GBCs}$ on a local scale is a priority to better assess $\mathrm{HM}$ contamination ${ }^{16}$. The two major origins of soil HMs are natural and anthropic sources ${ }^{17}$. The natural origin of HMs is related to soil parent materials, and anthropic sources are associated with various anthropogenic inputs, covering industrial production, agricultural activities and traffic emission ${ }^{18}$. Quantitative apportionment of possible origins of soil HMs is extremely important for the prevention and supervision of pollution ${ }^{19}$. Quantitative methods for source apportionment mainly included receptor models like absolute principal component scoring, chemical mass balance method and positive matrix factorization model (PMF). PMF method has been extensively applied to origin apportionment of atmosphere, sediment and water ${ }^{20-22}$. Recently, some achievements have been conducted in identifying the source of soil contaminants $s^{1,17,23}$. Apportioning HM sources in soils by PMF model is of great value to understand the characteristics and contributions of different origins. Hence, local authorities can take valid measures to decrease pollution emissions.

Over the years, the Hanjiang Delta (including Jiedong District), the second biggest economic zone after the Pearl River Delta in Guangdong Province, has witnessed rapid economic development. With this prerequisite, Jiedong District experienced fast development and industry optimization, forming an industrial structure with textile and garment, chemical plastics and metal manufacturing as the pillars. As to agriculture, cultivation and production have boomed. To be more specific, rice and other food crops have been planted as well as a large number of fruits such as litchi, longan and banana. In addition, its traffic advantages are also obvious. There are two expressways and two national highways running through the whole district. Those factors above: industrial activities, agricultural practices and heavy traffic in the study area provided a variety of sources of $\mathrm{HM}$ emissions. There are many studies on the evaluation and origin identification of soil HM contamination in counties and districts ${ }^{5,24,25}$, but few on the establishment of local GBCs for contamination evaluation.

The major targets of this study were: (1) to determine the GBCs of HMs in soil of the study area; (2) to evaluate HM pollution levels in combination with EF and PLI, and assess potential ecological risks by RI; (3) to quantitatively identify the possible sources of HMs using PMF model. This research provides a reference for establishing GBCs to more accurately assess HM pollution and source apportionment in those areas where local background values are lacking or inapplicable.

\section{Materials and methods}

Study region. Jiedong District is situated at the east part of Guangdong Province, South China (Fig. 1), which covers approximate $680 \mathrm{~km}^{2}$ and has a population of 1.2 million. The area has a subtropical monsoon climate, with annual mean precipitation and temperature of $1722 \mathrm{~mm}$ and $21.5^{\circ} \mathrm{C}$, respectively. Relying on the production base, Jiedong carries out the planting and processing of agricultural and sideline products. The main economic crops in the region cover bananas, citrus, longan and bamboo shoots. The industrial development of Jiedong District has formed an industrial layout of "one district and six parks" with the economic development zone as the leader and the six township industrial parks under the backbone.

Sample collections and analysis. In this research, we collected 212 topsoil $(0-20 \mathrm{~cm})$ and 52 subsoil $(150-$ $200 \mathrm{~cm}$ ) samples from Jiedong District (Fig. 1). The sampling densities of topsoil and subsoil were $4 \mathrm{~km}^{2}$ and 16 $\mathrm{km}^{2}$, respectively. Each soil sample was a synthesis of several sub-samples within 100 meters of the nearby sample site. All samples were gathered in polyethylene bags and brought back for chemical analysis. These samples were 
dried under daylight, and passed via $2.0 \mathrm{~mm}$ nylon sifters ${ }^{26}$. Contents of $8 \mathrm{HMs}(\mathrm{Cr}, \mathrm{Pb}, \mathrm{Ni}, \mathrm{Cu}, \mathrm{Zn}, \mathrm{Co}, \mathrm{V}$ and $\mathrm{Ti})$ were measured by $\mathrm{XRF}^{18}$. Soil samples were treated with $\mathrm{KMnO}_{4}-\mathrm{H}_{2} \mathrm{C}_{2} \mathrm{O}_{4}$ and the contents of As and $\mathrm{Hg}$ were determined by $\mathrm{AFS}^{17}$. Besides, partial samples were treated using $\mathrm{HNO}_{3}-\mathrm{HF}-\mathrm{HClO}_{4}$, and the content of Cd was determined by ICP-MS. We used standard references materials (GSS-1), replicate samples and reagent blanks for quality control. Four standard references, two blank samples and four duplicate samples were added to each batch of 50 samples. The relative standard deviations of repetitive sample did not exceed 5\%. The method detection limits (MDL) for $\mathrm{Cr}, \mathrm{Pb}, \mathrm{Ni}, \mathrm{Cu}, \mathrm{Zn}, \mathrm{Co}, \mathrm{V}, \mathrm{Ti}, \mathrm{As}, \mathrm{Hg}$ and $\mathrm{Cd}$ were 2, 1, 1, 1, 2, 0.8, 3, 10, 0.05, 0.0003 and $0.02 \mathrm{mg} /$ $\mathrm{kg}$, respectively.

Geochemical baseline concentrations. Geochemical baseline offers a method of identifying the natural and anthropic sources of HMs in soils and also play a critical role in assessment of HM pollution ${ }^{13,27}$. Subsoil samples $(150-200 \mathrm{~cm})$ were utilized to estimate the baseline concentrations of HMs in this study because they are largely unaffected by human activities. Furthermore, baseline concentrations were determined by applying the cumulative frequency distribution (CFD) curves $^{15}$. Kolmogorov-Smirnov (K-S) test was performed to verify the content distribution of each HM before plotting the CFD curves ${ }^{26,28}$. For CFD curves, the $\mathrm{x}$ axis shows the cumulative frequency, and the y axis shows the log-transformed values of the HM content or HM contents. And then the linear part of the CFD curve between the two inflection points is then applied to identify the baseline content of each HM. In this research, the inflexions in a curve were defined under the linear regression criteria for $\mathrm{P}<0.05$ and $\mathrm{R}^{2}>0.95$, and the extreme values were removed until the rest of data met the criteria of linearity ${ }^{15}$. The baseline values were determined by the following rules: If the curve had an inflection point, the baseline value was gained from the data below the inflection point; if the curve had two inflection points, the similarity of the data distribution between the two inflection points defined which inflection point was used as the basis for calculation. Finally, the data below the selected inflection point was averaged to obtain the baseline values.

Evaluation of soil contamination. To assess the contamination of HM in soil, EF and CF of selected HM as well as PLI of each sample site were calculated. EF is applied to evaluate the accumulation level of soil HMs. It is computed by Eq. (1) ${ }^{29}$ :

$$
\mathrm{EF}=\frac{\left(\mathrm{C}_{i} / \mathrm{B}_{\text {ref }}\right)_{\text {topsoils }}}{\left(\mathrm{C}_{i} / \mathrm{B}_{\text {ref }}\right)_{G B C s}}
$$

where $\mathrm{C}_{\mathrm{i}}$ represents the content of $\mathrm{HM}$, and $\mathrm{B}_{\text {ref }}$ represents the content of the reference metal. Generally, elements $\mathrm{Al}, \mathrm{Mn}, \mathrm{Fe}, \mathrm{Ti}$ and $\mathrm{Zr}$ are chosen as references ${ }^{30}$. In the study, Ti was selected due to the less impact of human activities $^{18}$. Based on the EF value, the enrichment classification of HM is as follows: negligible accumulation $(\mathrm{EF}<1)$; minor accumulation (1 2); moderate accumulation (2 5); major accumulation (5 20); high level accumulation (20 40); and exceedingly high accumulation $(\mathrm{EF} \geq 40)^{23}$.

$\mathrm{CF}$ and PLI were applied to evaluate the HM contamination in soils. $\mathrm{CF}_{\mathrm{i}}$ is the rate of the content of $\mathrm{HM}$ i to its corresponding GBC, and it shows the contamination level with a single $\mathrm{HM}$, as given below ${ }^{31}$ :

$$
C F_{i}=\frac{C_{i}}{C_{G B}}
$$

$\mathrm{CF}_{\mathrm{i}}$ is used to calculate the PLI value, which is computed via the following expression:

$$
P L I=\sqrt[n]{C F_{1} \times C F_{2} \times C F_{3} \times \cdots \times \times C F_{n}}
$$

Here, $\mathrm{C}_{\mathrm{i}}$ represents the contents of $\mathrm{HM}$ i and $\mathrm{C}_{\mathrm{GB}}$ represents the $\mathrm{GBC}$ of $\mathrm{HM}$ i. According to the research of Tomlinson et al. ${ }^{32}$, PLI $>1$ demonstrates HM contamination. Furthermore, the pollution levels are delimited as follow: no contamination (PLI $<1)$; moderate contamination $(1 \sim 2)$; severe contamination $(2 \sim 5)$; extreme contamination (PLI $\geq 5)$.

The RI presented by Hakanson ${ }^{33}$ is performed to investigate ecological risks caused by HMs. The RI is computed using below expression:

$$
\begin{gathered}
R I=\sum_{i=1}^{n} E_{i} \\
E_{i}=T_{i} * C F_{i}
\end{gathered}
$$

here, $E_{i}$ represents a single risk factor of $\mathrm{HM} \mathrm{i}$, and $\mathrm{T}_{\mathrm{i}}$ represents the toxic-response factor of $\mathrm{HM} \mathrm{i}$. The values of $\mathrm{T}_{\mathrm{i}}$ for $\mathrm{Zn}, \mathrm{V}, \mathrm{Cr}, \mathrm{Co}, \mathrm{Pb}, \mathrm{Ni}, \mathrm{Cu}, \mathrm{As}, \mathrm{Cd}$ and $\mathrm{Hg}$ were 1, 2, 2, 5, 5, 5, 5, 10, 30 and 40, respectively. Where $\mathrm{CF}_{\mathrm{i}}$ is the contamination factor of the HM i, which mentioned in Eq. (2). The RI could be calculated as the total of the $\mathrm{E}_{\mathrm{i}}$. Ecological risks based on the RI are divided into four categories ${ }^{33}$ : $\mathrm{RI}<150$ suggests a low ecological risk; 150 300 suggests a medium ecological risk, 300 600 suggests a significant ecological risk; and RI $>600$ suggests an extreme ecological risk.

PMF model. PMF was proposed and developed by Paatero and Tapper ${ }^{34}$, which is a multivariate receptor model for source apportionment. Based on EPA PMF 5.0 user manual: 


\begin{tabular}{|l|l|l|l|l|l|l|l|l|l|l|}
\hline & $\mathbf{C r}$ & $\mathbf{H g}$ & $\mathbf{A s}$ & $\mathbf{P b}$ & $\mathbf{N i}$ & $\mathbf{C d}$ & $\mathbf{C u}$ & $\mathbf{Z n}$ & $\mathbf{C o}$ & $\mathbf{V}$ \\
\hline Minimum & 4.80 & 0.03 & 0.80 & 18.60 & 2.70 & 0.05 & 2.90 & 36.50 & 1.67 & 20.70 \\
\hline Maximum & 117.20 & 1.05 & 120.00 & 122.70 & 34.80 & 1.39 & 63.50 & 316.30 & 16.10 & 131.38 \\
\hline Mean & 30.79 & 0.16 & 13.00 & 53.89 & 10.08 & 0.26 & 14.73 & 80.38 & 5.64 & 54.84 \\
\hline Median & 28.65 & 0.08 & 9.07 & 53.65 & 8.70 & 0.23 & 13.25 & 80.8 & 5.12 & 53.08 \\
\hline Standard deviation & 15.86 & 0.16 & 28.71 & 19.17 & 4.47 & 0.16 & 8.75 & 37.65 & 2.75 & 18.30 \\
\hline $\begin{array}{l}\text { Coefficient of } \\
\text { variation }\end{array}$ & 0.52 & 1.02 & 2.21 & 0.36 & 0.47 & 0.61 & 0.59 & 0.47 & 0.49 & 0.33 \\
\hline Grade II $^{\text {a }}$ & 150 & 0.3 & 40 & 250 & 40 & 0.3 & 50 & 200 & - & - \\
\hline
\end{tabular}

Table 1. Statistical summary of HMs in soils of Jiedong (mg/kg). a Data from CEPA (1995).

$$
\mathrm{x}_{i j}=\sum_{k=1}^{p} G_{i k} F_{k j}+E_{i j}
$$

here, $x_{i j}$ is a data matrix of HM j in sample $i$; $G_{i k}$ is the contribution matrix of source $k$ for sample $i$; and $F_{k j}$ is a factor profile of $\mathrm{HM} j$ for source factor $\mathrm{k}$. $\mathrm{E}_{\mathrm{ij}}$ represents the residual for $\mathrm{HM} \mathrm{j}$ from sample $\mathrm{i}$, and it can be acquired through minimizing the target function $\mathrm{Q}$ :

$$
Q=\sum_{i=1}^{n} \sum_{j=1}^{m}\left[\frac{\mathrm{x}_{i j}-\sum_{k=1}^{p} G_{i k} F_{k i}}{u_{i j}}\right]^{2}
$$

where $\mathrm{u}_{\mathrm{ij}}$ represents the uncertainty of $\mathrm{HM}$ j from sample $\mathrm{i}$, and it can be calculated using Eqs. (8)-(9):

$$
\text { if } \mathrm{c} \leq \mathrm{MDL}, u_{i j}=5 / 6 \times M D L
$$

$$
\text { or else, } u_{i j}=\sqrt{(\text { error fraction } \times c)^{2}+M D L^{2}}
$$

Date analysis. Descriptive statistics, such as median, mean, maximum, minimum, coefficient of variation and standard deviation, were used to characterize the contents of HMs in samples. Prior to calculation of GBCs, the K-S test was applied to determine whether HM content followed a normal distribution, and the logarithmic transformation was performed to normalize. In this work, all statistical analysis was carried out using SPSS 20 and Microsoft Excel 2007. ArcGIS 10.0 was performed to achieve the spatial maps, and the method of ordinary kriging was selected to interpolate the contents for these soil HMs.

\section{Results and discussion}

Content levels of soil HMs. Fundamental statistical characteristics of ten HMs in topsoils were presented in Table 1. The average contents of $\mathrm{Cr}, \mathrm{Hg}, \mathrm{As}, \mathrm{Pb}, \mathrm{Ni}, \mathrm{Cd}, \mathrm{Cu}, \mathrm{Zn}, \mathrm{Co}$ and V were 30.79, 0.16, 13.00, 53.89, 10.08, $0.26,14.73,80.38,5.64$ and $54.84 \mathrm{mg} / \mathrm{kg}$, respectively. The average concentrations of all $10 \mathrm{HMs}$ were below their corresponding national soil quality guideline values ${ }^{35}$. Among the samples, concentrations of Cd in 54 samples (25.47\%) and $\mathrm{Hg}$ in 37 samples (17.25\%) exceeded the Grade II values. Meanwhile, the highest contents of Cd and $\mathrm{Hg}$ were 4.63 and 3.50 times the corresponding secondary threshold levels, respectively. These indicated that contamination of $\mathrm{Cd}$ and $\mathrm{Hg}$ in Jiedong soil was relatively severe. However, the concentrations of other HMs were generally lower than secondary threshold levels. As for the coefficients of variation, $\mathrm{As}, \mathrm{Hg}, \mathrm{Cd}$ and $\mathrm{Cu}$ all have relatively high coefficients of variation, particularly As and Hg exceed 100\%. These suggested that these HMs were highly likely to be affected by human activities.

Establishment of GBCs. After passing the K-S test, the results showed that contents of HMs in subsoil samples were either normally distributed (for $\mathrm{Cr}, \mathrm{Pb}, \mathrm{Ni}, \mathrm{Cd}, \mathrm{Cu}, \mathrm{Zn}$, and $\mathrm{V}$ ) or log-normal distribution (for $\mathrm{Hg}$, As and Co). Therefore, the log-transformation was performed for the contents of $\mathrm{Hg}$, As, and Co, respectively. The baseline contents of all HMs were estimated by applying CFD curves and presented in Fig. 2 . The determined GBCs for Cr, Hg, As, Pb, Ni, Cd, Cu, Zn, Co and V were 39.91, 0.072, 11.48, 47.62, 12.70, 0.17, 14.22, 64.54, 6.31, and $68.14 \mathrm{mg} / \mathrm{kg}$, respectively. The estimated baseline contents were compared with background values (BVs) of World $^{36}$, China and Guangdong Province ${ }^{37}$, as well as another baseline concentration in Guangdong ${ }^{38}$ (Table 2). Except for $\mathrm{Hg}$, As and $\mathrm{Pb}$, the estimated baseline contents for $\mathrm{Cr}, \mathrm{Ni}, \mathrm{Cd}, \mathrm{Cu}, \mathrm{Zn}, \mathrm{Co}$ and $\mathrm{V}$ in Jiedong were much less than the world soils. It was found that the determined baseline contents of $\mathrm{Cr}, \mathrm{Ni}, \mathrm{Cu}$ and $\mathrm{Co}$ were less than their BVs in China and Guangdong Province. Meanwhile, the estimated baseline values of $\mathrm{As}, \mathrm{Pb}$ and $\mathrm{Cd}$ were higher than the BVs in China and Guangdong Province. For instance, the estimated baseline value of Cd was 1.75 times the BV of China and 3.04 times the BV of Guangdong Province. However, the baseline concentrations in this study were quite different from those of Guangdong Province in the study of Zhang et al. ${ }^{38}$. For example, the predicated baseline values of $\mathrm{Pb}, \mathrm{Cd}$ and $\mathrm{Zn}$ in this study were obviously greater than those in the study of Zhang et al. ${ }^{38}$. Therefore, it is necessary to establish GBCs based on Jiedong District to evaluate local soil HM pollution. 

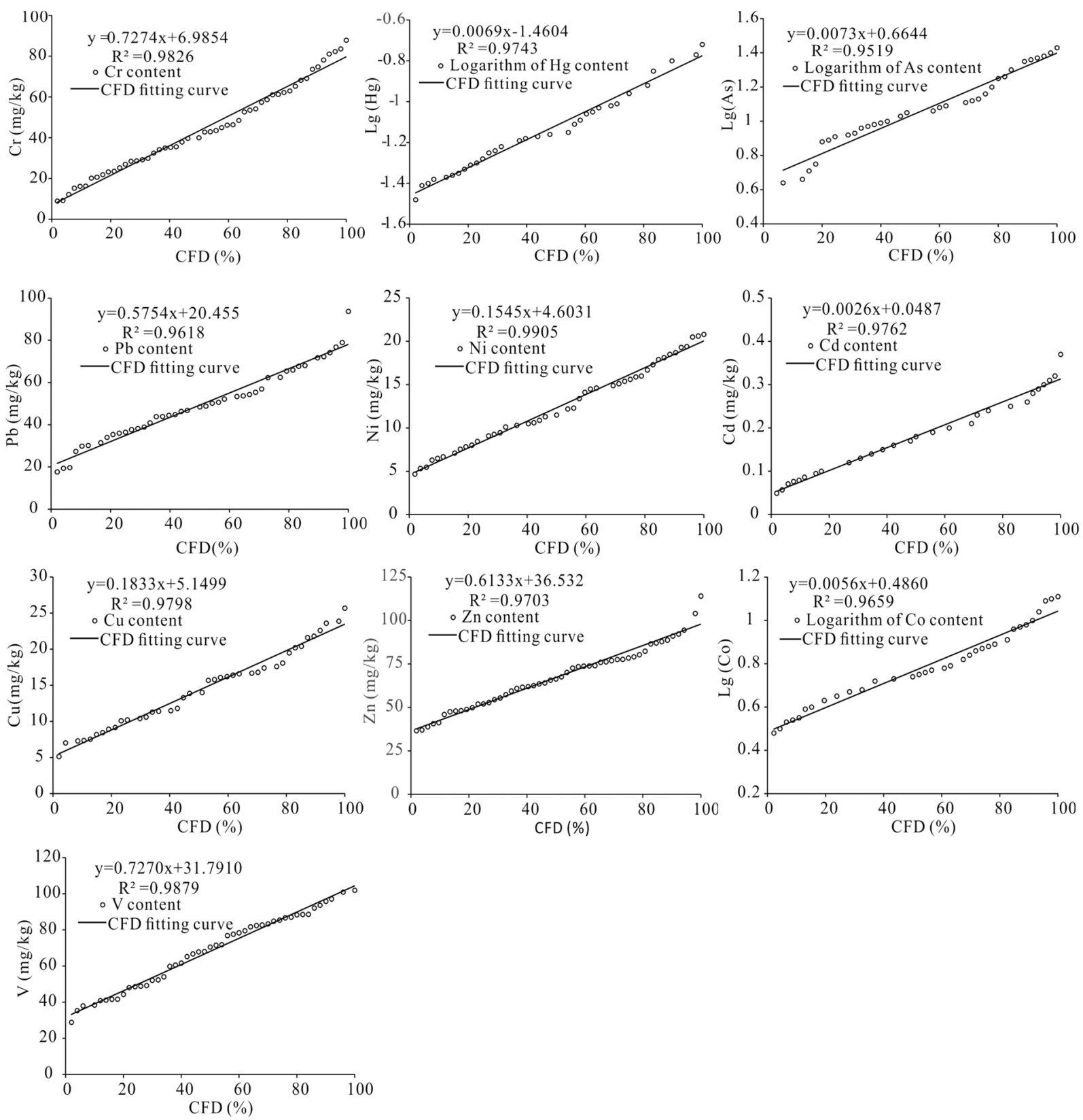

Figure 2. Cumulative frequency distribution curves of $10 \mathrm{HMs}$.

\begin{tabular}{|l|l|l|l|l|l|l|l|l|l|l|}
\hline & $\mathbf{C r}$ & $\mathbf{H g}$ & $\mathbf{A s}$ & $\mathbf{P b}$ & $\mathbf{N i}$ & $\mathbf{C d}$ & $\mathbf{C u}$ & $\mathbf{Z n}$ & $\mathbf{C o}$ & $\mathbf{V}$ \\
\hline $\begin{array}{l}\text { GBCs (this } \\
\text { study) }\end{array}$ & 39.91 & 0.072 & 11.48 & 47.62 & 12.70 & 0.17 & 14.22 & 64.54 & 6.31 & 68.14 \\
\hline $\begin{array}{l}\text { BVs of } \\
\text { Guangdong }\end{array}$ & 50.5 & 0.078 & 8.9 & 36.0 & 14.4 & 0.056 & 17.0 & 47.3 & 7.0 & 65.3 \\
\hline $\begin{array}{l}\text { BCs of } \\
\text { Guangdong }\end{array}$ & 57.8 & 0.10 & - & 37.5 & 18.0 & 0.10 & 18.0 & 51.4 & - & - \\
\hline BVs of China $^{\mathrm{a}}$ & 61.0 & 0.065 & 11.2 & 26.0 & 26.9 & 0.097 & 22.6 & 74.2 & 12.7 & 82.4 \\
\hline BVs of World $^{\mathrm{c}}$ & 59.5 & 0.07 & 6.83 & 27.0 & 29.0 & 0.41 & 38.9 & 70.0 & 11.3 & 129.0 \\
\hline
\end{tabular}

Table 2. Geochemical baseline concentrations determined in Jiedong and background values in other

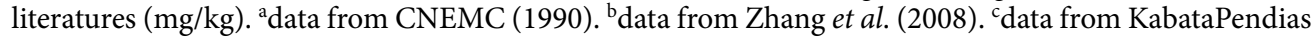
(2011). 


\begin{tabular}{|l|l|l|l|l|l|l|l|l|l|l|l|}
\hline \multicolumn{2}{|c|}{} & Cr & Hg & As & Pb & Ni & Cd & Cu & Zn & Co & V \\
\hline \multirow{3}{*}{ EF } & Minimum & 0.26 & 0.32 & 0.10 & 0.22 & 0.42 & 0.36 & 0.30 & 0.47 & 0.35 & 0.80 \\
\cline { 2 - 13 } & Maximum & 2.95 & 12.31 & 16.67 & 6.96 & 2.24 & 12.12 & 5.54 & 12.21 & 3.13 & 1.20 \\
\cline { 2 - 13 } & Mean & 0.91 & 2.54 & 1.32 & 1.56 & 0.95 & 2.01 & 1.25 & 1.63 & 0.98 & 0.95 \\
\hline \multirow{4}{*}{ CF } & Minimum & 0.12 & 0.37 & 0.07 & 0.40 & 0.21 & 0.33 & 0.20 & 0.57 & 0.26 & 0.30 \\
\cline { 2 - 13 } & Maximum & 2.93 & 14.62 & 10.45 & 2.58 & 2.74 & 8.44 & 4.47 & 4.90 & 2.55 & 1.93 \\
\cline { 2 - 12 } & Mean & 0.77 & 2.19 & 1.13 & 1.13 & 0.79 & 1.56 & 1.04 & 1.25 & 0.89 & 0.80 \\
\hline \multirow{3}{*}{$\mathrm{E}_{\mathrm{i}}$} & Minimum & 0.24 & 14.73 & 0.69 & 1.95 & 1.06 & 9.86 & 1.02 & 0.57 & 1.32 & 0.61 \\
\cline { 2 - 12 } & Maximum & 5.87 & 584.77 & 104.53 & 12.88 & 13.70 & 253.09 & 22.33 & 4.90 & 12.75 & 3.86 \\
\cline { 2 - 12 } & Mean & 1.54 & 87.42 & 11.33 & 5.66 & 3.97 & 46.87 & 5.18 & 1.25 & 4.47 & 1.61 \\
\hline
\end{tabular}

Table 3. EF, CF and $E_{i}$ values of HMs in soils of the study area.

Compared with these GBCs, the concentrations of $\mathrm{Hg}, \mathrm{As}, \mathrm{Pb}, \mathrm{Cd}$, and $\mathrm{Zn}$ in the topsoils in Jiedong District accumulated by $122 \%, 13 \%, 13 \%, 53 \%$, and $25 \%$, respectively. However, the mean content of Cu was only slightly higher than its GBC, and the average concentrations of $\mathrm{Cr}$, Ni and $\mathrm{V}$ were lower than their corresponding GBCs.

Evaluation of contamination and ecological risk of HMs. The results of EFs were presented in Table 3. The EF ranges of $\mathrm{Cr}, \mathrm{Hg}, \mathrm{As}, \mathrm{Pb}, \mathrm{Ni}, \mathrm{Cd}, \mathrm{Cu}, \mathrm{Zn}$, Co and V were 0.26-2.95, 0.32-12.31, 0.10-16.67, 0.22-6.96, $0.42-2.24,0.36-12.12,0.30-5.54,0.47-12.21,0.35-3.13$ and $0.80-1.20$, respectively, with an average value of 0.91 , $2.54,1.32,1.56,0.95,2.01,1.25,1.63,0.98$ and 0.95 , respectively. It was found that the mean EFs of $\mathrm{As}, \mathrm{Pb}, \mathrm{Cu}$ and $\mathrm{Zn}$ were in the range of 1 2, and the average $\mathrm{EFs}$ of $\mathrm{Hg}$ and $\mathrm{Cd}$ were greater than 2, indicating that these 6 HMs were likely to be primarily affected by anthropogenic activities. The average EFs of $\mathrm{Cr}, \mathrm{Ni}$, Co and $\mathrm{V}$ were $<1$, showing no accumulation and also revealing a natural source. The EFs for $\mathrm{Hg}$ in $75.94 \%$, As in $49.53 \%, \mathrm{~Pb}$ in $77.83 \%$, $\mathrm{Cd}$ in $89.15 \%, \mathrm{Cu}$ in $63.68 \%$ and $\mathrm{Zn}$ in $80.66 \%$ of soil samples were $>1$, suggesting that these HMs widely enriched in Jiedong. Especially for $\mathrm{Hg}$ and $\mathrm{Cd}, \mathrm{Hg}$ in $13.68 \%$ and $\mathrm{Cd}$ in $2.36 \%$ of all samples were major enrichment. In addition, the highest EF values of As (16.67) and $\mathrm{Zn}$ (12.21) showed major enrichment. All of these indicated that the soil HMs in Jiedong District were mainly slightly to moderately enriched, which also meant soils in Jiedong District were generally influenced by human activities.

The CFs of HMs were calculated and recorded in Table 3. The CF values for the selected HMs decreased as follow: $\mathrm{Hg}>\mathrm{Cd}>\mathrm{Zn}>\mathrm{As}=\mathrm{Pb}>\mathrm{Cu}>\mathrm{Co}>\mathrm{V}>\mathrm{Ni}>\mathrm{Cr}$. The CFs of $\mathrm{Hg}$ and $\mathrm{Cd}$ were relatively high, indicating that $\mathrm{Hg}$ and $\mathrm{Cd}$ in the study area exhibited moderate contamination. The average $\mathrm{CF}$ of $\mathrm{Cr}$, Ni, Co and $\mathrm{V}$ were $<1$, inferring no pollution of these $4 \mathrm{HMs}$, while the average $\mathrm{CFs}$ of $\mathrm{As}, \mathrm{Pb}, \mathrm{Cu}$ and $\mathrm{Zn}$ suggested slight pollution. The PLI value, based on further calculation of the CFs of $10 \mathrm{HMs}$, was useful to overall evaluate the level of soil HM pollution in Jiedong. The PLI values ranged from 0.47 to 2.22 . There were 123 sampling sites with PLI values lower than 1, 87 sampling sites with PLI values ranging from 1 to 2 , and 2 sampling sites with PLI values ranging from 2 to 5 . The above revealed that approximately $58.02 \%$ of the sampling sites were not polluted by HMs, $41.04 \%$ of the sampling sites were moderately polluted, and $0.94 \%$ of the sampling sites were severely polluted.

Considering that different pollutants have different toxicity to human body, RI was used to comprehensively evaluate the ecological risks of soil HMs. Single risk indexes $\left(E_{i}\right)$ were shown in Table 3 . The mean $E_{i}$ values of ten $\mathrm{HMs}$ were ranked according to intensity of ecological risk as: $\mathrm{Hg}$ » $\mathrm{Cd} » \mathrm{As}>\mathrm{Pb}>\mathrm{Cu}>\mathrm{Co}>\mathrm{Ni}>\mathrm{V}>\mathrm{Cr}>$ $\mathrm{Zn}$. Based on the classification criteria of Hakanson ${ }^{33}$, the mean $\mathrm{E}_{\mathrm{i}}$ values of $\mathrm{Hg}$ (87.42) and Cd (46.87) belong to considerable and moderate single potential ecological risk, respectively. Nevertheless, the mean $\mathrm{E}_{\mathrm{i}}$ values for $\mathrm{Cr}$, $\mathrm{As}, \mathrm{Pb}, \mathrm{Ni}, \mathrm{Cu}, \mathrm{Zn}$, Co and $\mathrm{V}$ were $<40$, indicating these $8 \mathrm{HMs}$ show the low degree of potential ecological risk. Integrated potential ecological risk assessment of $10 \mathrm{HMs}$ presented that RI values in $58.96 \%$ of the sampling sites were $<150$, suggesting that the ecological risks in most areas of the region were low. The RI values of 61 sampling sites ranged from 150 to 300 , inferring that $28.77 \%$ of the study area had medium ecological risk. And the RI values of 24 sampling sites were in the range of 300 and 600 , indicating a significant ecological risk in $11.32 \%$ of the study area. However, it is worth noting that $0.94 \%$ of the area faced an extreme ecological risk from soil HMs.

Spatial distribution of HMs in soils. The spatial distributions of HM content are useful to distinguish hotspots and identify the possible sources of HMs in soils. The spatial variations of $10 \mathrm{HMs}$ in Jiedong District were presented in Fig. 3. Spatial variation tendencies of $\mathrm{Cu}$ and As were approximately similar, and these hot spots were situated at the western and eastern parts of the study area, where agricultural production regions were concentrated. inputs from agricultural activities, for instance, fertilizers, herbicides and pesticides, contain large amounts of $\mathrm{As}$ and $\mathrm{Cu}^{39,40}$, which contribute to the accumulation of As in the soil of Jiedong District.

As presented in Fig. 3, spatial variations of $\mathrm{Pb}$ and $\mathrm{Zn}$ were highly consistent, and high content areas of $\mathrm{Pb}$ and $\mathrm{Zn}$ were found at the middle of Jiedong District, which suggested that $\mathrm{Pb}$ and $\mathrm{Zn}$ may come from the same origin. These hotspots of $\mathrm{Pb}$ and $\mathrm{Zn}$ were observed near major roads and urban areas where traffic and population were quite intensive. It is reported that common origins of $\mathrm{Pb}$ and $\mathrm{Zn}$ are traffic emissions ${ }^{41,42}$. In addition, $\mathrm{Zn}$ as a necessary micronutrient for plant, excessive or insufficient zinc in soil will affect plant growth. According to the spatial distribution of $\mathrm{Zn}$, the eastern crop growing area of Jiedong District may face $\mathrm{Zn}$ deficiency, while the southern area may face $\mathrm{Zn}$ excess.

The spatial trends of $\mathrm{Hg}$ and $\mathrm{Cd}$ contents were highly similar and relatively concentrated (Fig. 3). Soils with high concentrations of $\mathrm{Hg}$ and $\mathrm{Cd}$ were detected in the south and east of Jiedong District. Major industrial parks, 


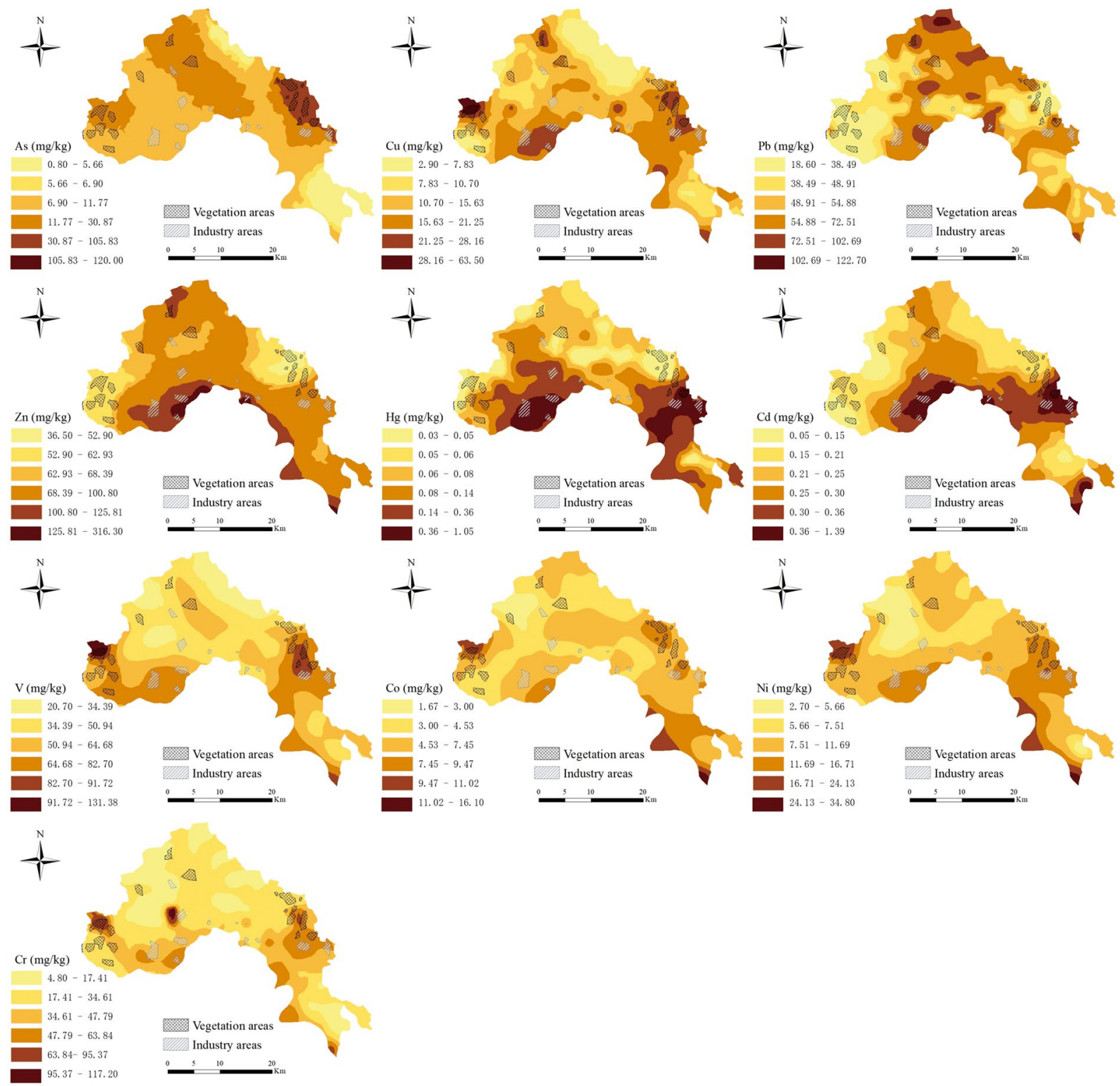

Figure 3. Spatial distribution of $10 \mathrm{HMs}$ in soils across study area.

such as textile mills, pharmaceutical factories and metal manufacturing factories were widely distributed in these areas. These related industries have been demonstrated to cause the enrichment of $\mathrm{Hg}$ and Cd in soils via atmospheric deposition ${ }^{43,44}$.

According to Fig. 3, it revealed the overall downward trend of $\mathrm{V}, \mathrm{Co}, \mathrm{Ni}$ and $\mathrm{Cr}$ concentrations from southern to northern. The high values of these $4 \mathrm{HMs}$ were focused on the southwest and southeast edge of Jiedong District, where most of them were natural vegetation areas and were less influenced by anthropogenic activities. Additionally, the average concentrations of $\mathrm{V}, \mathrm{Co}, \mathrm{Ni}$ and $\mathrm{Cr}$ were less than their GBCs, and their EF values were also low. Therefore, it suggested that $\mathrm{V}, \mathrm{Co}, \mathrm{Ni}$ and $\mathrm{Cr}$ may have the same origin, which was determined by the parent material.

Source apportionment by PMF. The input files of PMF model contained concentration data of $10 \mathrm{HMs}$ in 212 samples and uncertainty data associated with these concentrations. The most appropriate number of factor solutions were chosen according to the minimum and steady $Q$ value, and the optimal factor number, that is, four factors were achieved. Here, the residual value of most soil samples was in the range of $-3 \sim 3$. The $\mathrm{R}^{2}$ values represented determination coefficients of $10 \mathrm{HMs}$, all of which were greater than 0.75 . These indicated that the results were reliable, and four factors produced by PMF operation were presented in Fig. 4.

Factor 1 was dominated by $\mathrm{Hg}(64.76 \%)$ and Cd (35.07\%) (Fig. 4), which accounted for $20.61 \%$ of the total variance. Elements $\mathrm{Hg}$ and $\mathrm{Cd}$ had relatively high coefficients of variation, indicating that they were greatly influenced by human activities. Meanwhile, $\mathrm{Hg}$ in $75.94 \%$ of the samples and $\mathrm{Cd}$ in $89.15 \%$ of the samples were accumulated, and the highest EF exceeded 10, which belonged to major accumulation. All these inferred that $\mathrm{Hg}$ and 


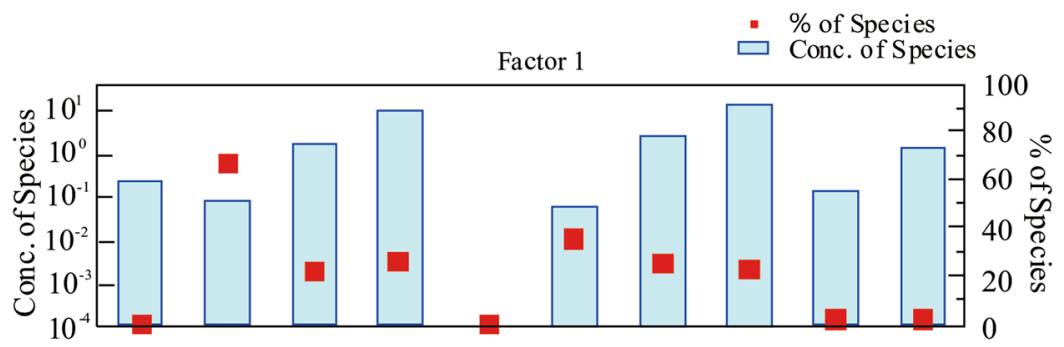

Factor 2

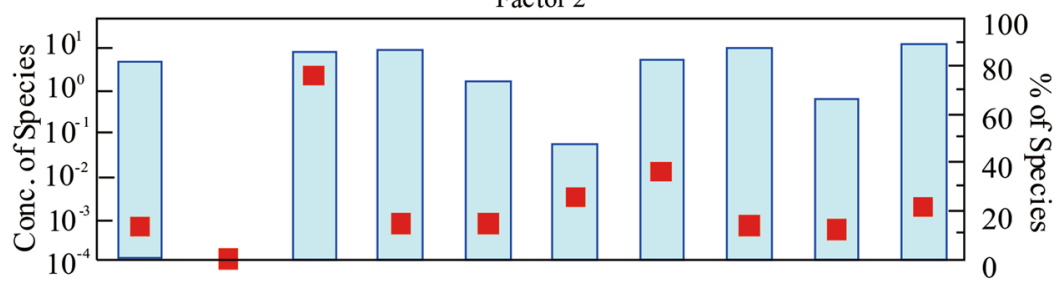

Factor 3

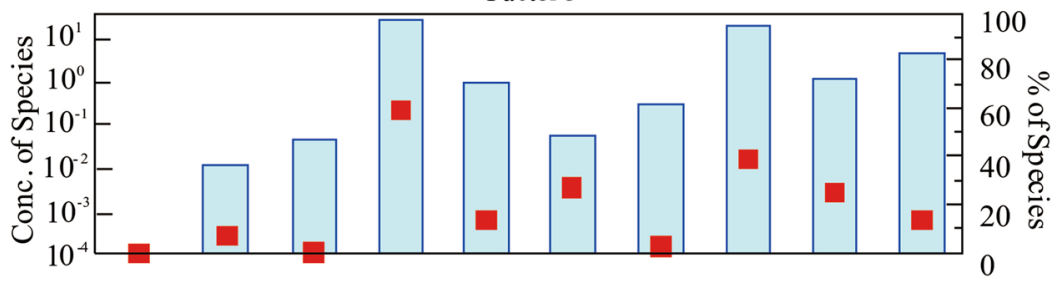

Factor 4

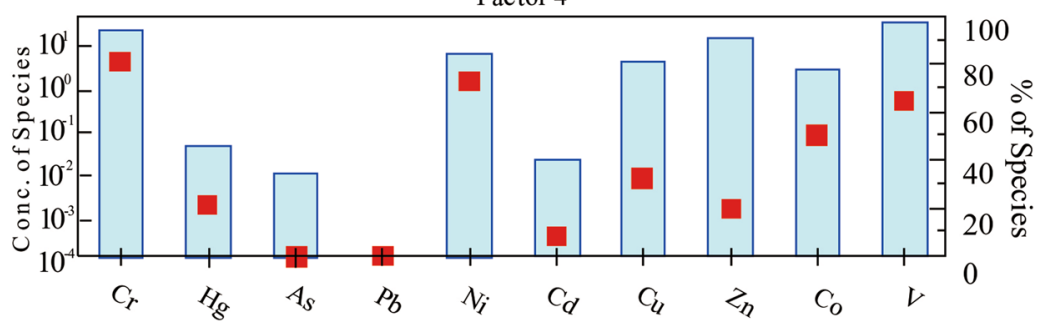

Figure 4. Factor profiles and contribution percentage of HMs from PMF model.

Cd might come from anthropogenic sources. Dvonch et al. ${ }^{45}$ reported that about $80 \%$ of total $\mathrm{Hg}$ originated from human activities, and the vast majority of $\mathrm{Hg}$ was released into the atmosphere in the form of vapor. Meanwhile, previous studies have presented that $\mathrm{Hg}$ enrichment in soils is mainly related to industrial activities, such as the burning of fossil fuels, smelting, and the manufacture of chemical raw materials and chemicals ${ }^{25,46,47}$. Cadmium is mainly used in the manufacture of batteries, pigments, alloys and electroplating, and as a stabilizer for plastic products. It is therefore generally regarded as the marker element of industry ${ }^{48}$. According to the survey of JPGP (Jieyang People's Government Portal) ${ }^{49}$, textile and garment industry, rubber and plastics manufacturing, metal smelting and manufacturing accounted for $8.24 \%, 14.56 \%$ and $17.88 \%$ of the total industry in Jiedong District, respectively. Moreover, there were a number of chemical plants and pharmaceutical factories in the study area. Therefore, the waste water, waste gas and waste residue generated by all these industries were the major origins of soil $\mathrm{Hg}$ and $\mathrm{Cd}$ in Jiedong. As analyzed above, Factor 1 could be determined as industrial activities.

Factor 2 accounted for $24.20 \%$ of the source contribution, and was predominated by As (77.90\%) and Cu (37.83\%) (Fig. 4). As mentioned above, the average EFs of As and $\mathrm{Cu}$ were $>1$, and the maximum EFs of As and $\mathrm{Cu}$ were 16.67 and 5.54, respectively, both of which were major enrichment. Moreover, the spatial distributions of $\mathrm{As}$ and $\mathrm{Cu}$ revealed that their high-value regions were distributed in the eastern part of Jiedong District, which was consistent with the agricultural planting areas. Arsenic and $\mathrm{Cu}$ are often associated with agricultural practices, including the use of pesticides and fertilizers. Pesticides or herbicides used in agricultural production contain large amounts of inorganic arsenic compounds, such as sodium arsenate and calcium arsenate ${ }^{18}$. Many researches ${ }^{50,51}$ have shown that As was predominantly found in phosphate fertilizers, which is also an important pathway for As to seep into the soil. Livestock manures and pesticides are the major origins of $\mathrm{Cu}$ in soils. Copper and its compounds are mainly applied in fungicides and pesticides ${ }^{23}$. It is investigated that $69 \%$ of $\mathrm{Cu}$ in soils is derived from livestock manure ${ }^{52}$. According to the statistical yearbook ${ }^{49}$, the application of pesticides and fertilizers applied to cultivated land in Jiedong District was $80 \mathrm{~kg} / \mathrm{ha}$ and $3140 \mathrm{~kg} / \mathrm{ha}$, respectively. Furthermore, 
in China, the utilization rate of pesticides and fertilizers is commonly low, about $70 \%$ of which is lost to the surroundings ${ }^{23}$. Consequently, Factor 2 was defined as agricultural practices.

For the third factor, it was identified by $\mathrm{Pb}(58.40 \%)$ and $\mathrm{Zn}(42.08 \%)$ (Fig. 4), which explained $19.22 \%$ of the total contribution. The concentrations of $\mathrm{Pb}$ and $\mathrm{Zn}$ in most soils were greater than GBCs, especially for $\mathrm{Zn}$, which was 1.53 times the GBC. Meanwhile, the EFs of $\mathrm{Pb}$ and $\mathrm{Zn}$ showed a relatively high level of enrichment. These indicated that $\mathrm{Pb}$ and $\mathrm{Zn}$ in Jiedong District came from human input. Normally, $\mathrm{Pb}$ is considered as a sign of transportation ${ }^{46}$. Although leaded gasoline has been banned since 2000, $\mathrm{Pb}$ enrichment still exists due to the use of leaded gasoline for several decades ${ }^{53}$. While braking device and clutch wear of automobile are other origins of $\mathrm{Pb}^{54}$. As for $\mathrm{Zn}$, the abrasion of vehicle tyres and the corrosion of galvanized of vehicle components lead to the enrichment of $\mathrm{Zn}$ in the soil ${ }^{41,55}$. Xia et al ${ }^{56}$ reported the contents of $\mathrm{Pb}$ and $\mathrm{Zn}$ in roadside soil were obviously positively correlated with transportation density. Besides, according to the spatial distribution of $\mathrm{Pb}$ and $\mathrm{Zn}$, the contents of $\mathrm{Pb}$ and $\mathrm{Zn}$ were high near those main roads (expressways and national highways) (Fig. 3). Similar results have been summarized in many other researches ${ }^{2,10,57}$. From what has been discussed above, Factor 3 was considered as traffic emissions.

Factor 4 was characterized by descending order of $\mathrm{Cr}, \mathrm{Ni}, \mathrm{V}, \mathrm{Co}$ and $\mathrm{Cu}$, with contribution rates of $81.03 \%$, $71.60 \%, 63.69 \%, 53.87 \%$ and $31.86 \%$, respectively (Fig. 4). This source was the biggest factor and taken over $35.97 \%$ of the total variance. Except that the mean content of $\mathrm{Cu}$ was slightly higher than its $\mathrm{GBC}$, the averages of the other $4 \mathrm{HMs}$ were lower than their corresponding GBCs. Moreover, the EF values of these HMs revealed that most soils had no accumulation. For example, the ratio of EF values $<1$ in the study area presented $66.98 \%$ of $\mathrm{Cr}$, $66.68 \%$ of $\mathrm{Ni}$ and $68.40 \%$ of $\mathrm{V}$. All these indicated that this group of HMs came from a natural origin. Previous researches have similar conclusions. Franco-Uría et al. ${ }^{58}$ studied soil HMs in Pastoriza (Spain), and found that $\mathrm{Cu}$, $\mathrm{Ni}$ and Co were correlated with two lithogenic components. Cai et al..$^{59}$ reported that $\mathrm{Co}, \mathrm{Cr}$, and Ni were related to soil parent material. In addition, the study from the Lv et al. ${ }^{25}$ in Ju Country (China) suggested V, Ni, Cr, Co and partially $\mathrm{Cu}$ originated from natural source. Thus, Factor 4 was classified as a natural source.

Fig. S1 illustrated the percentage of four sources in the total variance percentage. Natural source (35.97\%) was assigned as the biggest contribution rate of HMs in the soil of Jiedong District, followed by agricultural practices $(24.20 \%)$, industrial activities (20.61\%) and traffic emissions (19.22\%). In short, anthropogenic sources (64.03\%) dominated the total contribution rate, which was the main factor affecting the content of soil HMs in Jiedong District. The use of pesticides, livestock manures and fertilizers, textile and garment processing, plastic and rubber production, metal manufacturing, and vehicle emissions were considered as the major origins of HM contamination in Jiedong District. In other words, anthropogenic activities posed a tremendous influence on the accumulation of soil HMs in Jiedong District. Therefore, in order to control and alleviate the contamination of soil HMs in Jiedong, agricultural production, industrial activities, and transportation should be regulated and adjusted.

\section{Conclusion}

In this research, the GBCs of $\mathrm{Cr}, \mathrm{Hg}, \mathrm{As}, \mathrm{Pb}, \mathrm{Ni}, \mathrm{Cd}, \mathrm{Cu}, \mathrm{Zn}$, $\mathrm{Co}$ and $\mathrm{V}$ were established, which were 39.91, 0.072, $11.48,47.62,12.70,0.17,14.22,64.54,6.31$, and $68.14 \mathrm{mg} / \mathrm{kg}$, respectively. The average concentrations of $\mathrm{Hg}, \mathrm{As}$, $\mathrm{Pb}, \mathrm{Cd}, \mathrm{Cu}$ and $\mathrm{Zn}$ were greater than corresponding GBCs, especially for $\mathrm{Cd}$ and $\mathrm{Hg}$, which were 1.53 and 2.22 times their GBCs. Meanwhile, the concentrations of $\mathrm{Hg}$ in 37 samples (17.25\%) and Cd in 54 samples (25.47\%) exceeded the Grade II values. The EF and PLI suggested moderate HM pollution, but contamination of Hg and $\mathrm{Cd}$ was more serious. And the RI values showed that the potential ecological risks were low in most parts of the total area. Analysis based on EF, geostatistics and PMF, four sources were identified. Lead and Zn were mainly related to traffic emissions. Mercury and Cd mainly derived from industrial activities, such as textile and garment processing, plastic and rubber production and metal manufacturing. Arsenic and part of Cu mainly came from agricultural inputs, including the use of fertilizers, livestock manures and pesticides. Chromium, Ni, V, Co, and part of $\mathrm{Cu}$ were originated from natural source associated with parent materials. This research highlighted the demand to determine regional GBCs as an important foundation for accurate HM pollution evaluations. Furthermore, this study also offers a reference for preventing and controlling soil HM pollution by proposing the management of these anthropogenic sources.

\section{Data availability}

The data in this article is available.

Received: 29 October 2019; Accepted: 31 March 2020;

Published online: 15 April 2020

\section{References}

1. Guan, Q. et al. Source apportionment of heavy metals in agricultural soil based on PMF: A case study in Hexi Corridor, northwest China. Chemosphere. 193, 189-197 (2018).

2. Huang, J. et al. A new exploration of health risk assessment quantification from sources of soil heavy metals under different land use. Environmental Pollution. 243, 45-58 (2018).

3. Tepanosyan, G. et al. Human health risk assessment and riskiest heavy metal origin identification in urban soils of Yerevan, Armenia. Chemosphere. 184, 1230 (2017).

4. Cai, L. M. et al. Heavy metal contamination and health risk assessment for children near a large $\mathrm{Cu}$-smelter in central China. Science of the Total Environment. 650, 725-733 (2019).

5. Pan, L. B. et al. Heavy metals in soils from a typical county in Shanxi Province. China: Levels, sources and spatial distribution. Chemosphere. 148, 248-254 (2016).

6. Salazar, M. J. et al. Effects of heavy metal concentrations $(\mathrm{Cd}, \mathrm{Zn}$ and $\mathrm{Pb})$ in agricultural soils near different emission sources on quality, accumulation and food safety in soybean [Glycine max (L.) Merrill]. Journal of Hazardous Materials. 233-234, 244-253 (2012). 
7. Ali, B. et al. Heavy metal contamination from mining sites in South Morocco: 1 . Use of a biotest to assess metal toxicity of tailings and soils. Chemosphere. 63(5), 802-810 (2006).

8. Bernard, A. Cadmium \& its adverse effects on human health. Indian Journal of Medical Research. 128(4), 557 (2008).

9. Pizzol, M., Thomsen, M. \& Andersen, M. S. Long-term human exposure to lead from different media and intake pathways. Science of the Total Environment. 408(22), 5478-5488 (2010).

10. Tepanosyan, G. et al. Origin identification and potential ecological risk assessment of potentially toxic inorganic elements in the topsoil of the city of Yerevan, Armenia. Journal of Geochemical Exploration. 167, 1-11 (2016).

11. Yuan, G. L. et al. Source identification and ecological risk assessment of heavy metals in topsoil using environmental geochemical mapping: Typical urban renewal area in Beijing, China. Journal of Geochemical Exploration. 136(1), 40-47 (2014).

12. Matschullat, J., Ottenstein, R. \& Reimann, C. Geochemical background - can we calculate it? Environmental Geology. 39(9), 990-1000 (2000).

13. Sierra, M., Martínez, F. J. \& Aguilar, J. Baselines for trace elements and evaluation of environmental risk in soils of Almeria (SE Spain). Geoderma. 139, 209-219 (2007).

14. Li, Y. et al. Evaluation of the Possible Sources and Controlling Factors of Toxic Metals/Metalloids in the Florida Everglades and Their Potential Risk of Exposure. Environmental Science \& Technology. 49(16), 9714-23 (2015).

15. Tian, K. et al. Geochemical baseline establishment and ecological risk evaluation of heavy metals in greenhouse soils from Dongtai, China. Ecological Indicators. 72, 510-520 (2017).

16. Kelepertzis, E., Galanos, E. \& Mitsis, I. Origin, mineral speciation and geochemical baseline mapping of $\mathrm{Ni}$ and $\mathrm{Cr}$ in agricultural topsoils of Thiva Valley (central Greece). Journal of Geochemical Exploration. 125(1), 56-68 (2013).

17. Liang, J. et al. Spatial distribution and source identification of heavy metals in surface soils in a typical coal mine city, Lianyuan, China. Environmental Pollution. 225, 681-690 (2017).

18. Wang, S. et al. Spatial distribution and source apportionment of heavy metals in soil from a typical county-level city of Guangdong Province, China. The Science of the total environment. 655, 92-101 (2019).

19. Liu, J. et al. Quantitative contributions of the major sources of heavy metals in soils to ecosystem and human health risks: A case study of Yulin, China. Ecotoxicology and Environmental Safety. 164, 261-269 (2018).

20. Bzdusek, P. A., Jianhang, L. A. \& Christensen, E. R. PCB Congeners and Dechlorination in Sediments of Sheboygan River, Wisconsin, Determined by Matrix Factorization. Environmental Science \& Technology. 40(1), 120-9 (2006).

21. Jaeckels, J. M., Minsuk Bae, A. \& Schauer, J. J. Positive Matrix Factorization (PMF) Analysis of Molecular Marker Measurements to Quantify the Sources of Organic Aerosols. Environmental Science \&. Technology. 41(16), 5763-5769 (2007).

22. Zou, Y. et al. Debromination of PBDEs in Arkansas Water Bodies Analyzed by Positive Matrix Factorization. Environmental Science \& Technology. 50(3), 1359 (2016).

23. Cai, L.-M., Jiang, H.-H. \& Luo, J. Metals in soils from a typical rapidly developing county, Southern China: levels, distribution, and source apportionment. Environmental Science and Pollution Research. 26, 19282-19293 (2019).

24. Ağca, N. \& Özdel, E. Assessment of spatial distribution and possible sources of heavy metals in the soils of Sariseki-Dörtyol District in Hatay Province (Turkey). Environmental Earth Sciences. 71(3), 1033-1047 (2014).

25. Lv, J. et al. Identifying the origins and spatial distributions of heavy metals in soils of Ju country (Eastern China) using multivariate and geostatistical approach. Journal of Soils \& Sediments. 15(1), 163-178 (2015).

26. Karim, Z., Qureshi, B. A. \& Mumtaz, M. Geochemical baseline determination and pollution assessment of heavy metals in urban soils of Karachi, Pakistan. Ecological Indicators. 48(48), 358-364 (2014).

27. Hamon, R. et al. Geochemical indices allow estimation of global heavy metal background concentrations in soils. Global Biogeochemical Cycles. 18(1), GB1014 (2004).

28. Wei, C. \& wen, H. Geochemical baselines of heavy metals in the sediments of two large freshwater lakes in China: implications for contamination character and history. Environmental Geochemistry \& Health. 34(6), 737-748 (2012).

29. Gowd, S. S., Reddy, M. R. \& Govil, P. K. Assessment of heavy metal contamination in soils at Jajmau (Kanpur) and Unnao industrial areas of the Ganga Plain, Uttar Pradesh, India. Journal of Hazardous Materials. 174(1), 113-121 (2010).

30. Li, H. et al. Chemical fractionation of arsenic and heavy metals in fine particle matter and its implications for risk assessment: A case study in Nanjing, China. Atmospheric Environment. 103, 339-346 (2015).

31. Muller, G. Index of geoaccumulation in sediments of the Rhine River. Geojournal. 2(108), 108-118 (1969).

32. Tomlinson, D. L. et al. Problems in the assessment of heavy-metal levels in estuaries and the formation of a pollution index. Helgoländer Meeresuntersuchungen. 33(1-4), 566-575 (1980).

33. Hakanson, L. An ecological risk index for aquatic pollution control.a sedimentological approach. Water Research. 14(8), 975-1001 (1980).

34. Paatero, P. \& Tapper, U. Positive matrix factorization: A non-negative factor model with optimal utilization of error estimates of data values. Environmetrics. 5(2), 111-126 (2010).

35. CEPA Environmental Quality Standard for Soils (GB15618-1995). Chinese Environmental Protection Administration. (1995).

36. KabataPendias, A. Trace elements in soils and plants CRC Press. (2011).

37. CNEMC The Backgrounds of Soil Environment in China. China Environmental Science Press. (1990).

38. Zhang, H. H. et al. Baseline concentrations and spatial distribution of trace metals in surface soils of Guangdong province, China. Journal of Environmental Quality. 37(5), 1752 (2008).

39. Bhattacharya, P. et al. Arsenic in the environment: Biology and Chemistry. Science of the Total Environment. 379(2), 109-120 (2007).

40. Çolak, M. Heavy metal concentrations in sultana-cultivation soils and sultana raisins from Manisa (Turkey). Environmental Earth Sciences. 67(3), 695-712 (2012).

41. Li, X., Poon, C. S. \& Liu, P. S. Heavy metal contamination of urban soils and street dusts in Hong Kong. Applied Geochemistry. 16(11), 1361-1368 (2001).

42. Mielke, H. W., Laidlaw, M. A. S. \& Gonzales, C. Lead ( $\mathrm{Pb})$ legacy from vehicle traffic in eight California urbanized areas: continuing influence of lead dust on children's health. Science of the Total Environment. 408(19), 3965 (2010).

43. Berg, T., Fjeld, E. \& Steinnes, E. Atmospheric mercury in Norway: Contributions from different sources. Science of the Total Environment. 368(1), 3-9 (2006).

44. Shan, W. et al. Levels and health risk assessments of heavy metals in urban soils in Dongguan, China. Journal of Geochemical Exploration. 148(148), 71-78 (2015)

45. Dvonch, J. T. et al. Use of Elemental Tracers to Source Apportion Mercury in South Florida Precipitation. Environmental Science \& Technology. 33(24), 4522-4527 (1999).

46. Cai, L. et al. Heavy metals in agricultural soils from a typical township in Guangdong Province, China: Occurrences and spatial distribution. Ecotoxicology \& Environmental Safety. 168, 184-191 (2019).

47. Davis, H. T. et al. Identifying natural and anthropogenic sources of metals in urban and rural soils using GIS-based data, PCA, and spatial interpolation. Environmental Pollution. 157(8), 2378-2385 (2009).

48. Foti, L. et al. Trace element concentrations along a gradient of urban pressure in forest and lawn soils of the Paris region (France). Science of the Total Environment. 598, 938-948 (2017).

49. JPGP (Jieyang People’s Government Portal) Statictical yearbook of Jieyang City, http://www.jieyang.gd.cn/bumen/tij/tjsj_nj/detail/ EAD0D03FCA2C1299 (2017) 
50. Ahmed, K. M. et al. Arsenic enrichment in groundwater of the alluvial aquifers in Bangladesh: an overview. Applied Geochemistry. 19(2), 181-200 (2004).

51. Nziguheba, G. \& Smolders, E. Inputs of trace elements in agricultural soils via phosphate fertilizers in European countries. Science of the Total Environment. 390(1), 53-57 (2008).

52. Luo, L. et al. An inventory of trace element inputs to agricultural soils in China. Journal of Environmental Management. 90(8), 2524-2530 (2009).

53. Chen, H. et al. Source apportionment and health risk assessment of trace metals in surface soils of Beijing metropolitan, China. Chemosphere. 144, 1002-1011 (2016).

54. Adamiec, E., Jarosz-Krzeminska, E. \& Wieszala, R. Heavy metals from non-exhaust vehicle emissions in urban and motorway road dusts. Environmental Monitoring and Assessment. 188(6), 369 (2016).

55. Yadav, I. C. et al. Spatial distribution, source analysis, and health risk assessment of heavy metals contamination in house dust and surface soil from four major cities of Nepal. Chemosphere. 218, 1100-1113 (2019).

56. Xia, X. et al. Heavy metals in urban soils with various types of land use in Beijing, China. Journal of Hazardous Materials. 186(2-3), 2043-2050 (2011).

57. Jiang, H. et al. An integrated approach to quantifying ecological and human health risks from different sources of soil heavy metals. Science of the Total Environment. 701 (2020).

58. Franco-Uría, A. et al. Source identification of heavy metals in pastureland by multivariate analysis in NW Spain. Journal of Hazardous Materials. 165(1), 1008-1015 (2009).

59. Cai, L. et al. Multivariate and geostatistical analyses of the spatial distribution and source of arsenic and heavy metals in the agricultural soils in Shunde, Southeast China. Journal of Geochemical Exploration. 148, 189-195 (2015).

\section{Acknowledgements}

This work is funded by the National Natural Science Foundation of China (41201043).

\section{Author contributions}

Hui-Hao Jiang, Li-Mei Cai and Han-Hui Wen designed the sampling plan and conducted specific sampling work. Hui-Hao Jiang and Jie Luo performed the experiments and data analysis. Hui-Hao Jiang wrote the manuscript and Li-Mei Cai reviewed the manuscript.

\section{Competing interests}

The authors declare no competing interests.

\section{Additional information}

Supplementary information is available for this paper at https://doi.org/10.1038/s41598-020-63604-5.

Correspondence and requests for materials should be addressed to L.-M.C.

Reprints and permissions information is available at www.nature.com/reprints.

Publisher's note Springer Nature remains neutral with regard to jurisdictional claims in published maps and institutional affiliations.

(c) (i) Open Access This article is licensed under a Creative Commons Attribution 4.0 International

License, which permits use, sharing, adaptation, distribution and reproduction in any medium or format, as long as you give appropriate credit to the original author(s) and the source, provide a link to the Creative Commons license, and indicate if changes were made. The images or other third party material in this article are included in the article's Creative Commons license, unless indicated otherwise in a credit line to the material. If material is not included in the article's Creative Commons license and your intended use is not permitted by statutory regulation or exceeds the permitted use, you will need to obtain permission directly from the copyright holder. To view a copy of this license, visit http://creativecommons.org/licenses/by/4.0/.

(C) The Author(s) 2020 